\title{
Colonization of novel algal habitats by juveniles of a marine tube-dwelling amphipod
}

\author{
Marilia Bueno ${ }^{\text {Corresp., } 1}$, Glauco B O Machado ${ }^{1,2}$, Fosca Leite ${ }^{1}$ \\ 1 Departamento de Biologia Animal, Universidade Estadual de Campinas, Campinas, São Paulo, Brazil \\ 2 Instituto de Biociências, Campus do Litoral Paulista, Universidade Estadual Paulista, São Vicente, São Paulo, Brazil \\ Corresponding Author: Marilia Bueno \\ Email address: mariliabueno@live.com
}

Background. Dispersal is an important process affecting population dynamics and connectivity. For marine direct developers, both adults and juveniles may disperse. Although the distribution of juveniles can be initially constrained by their mothers' choice, they may be able to leave the parental habitat and colonize other habitats. We investigated the effect of habitat quality, patch size and presence of conspecific adults on the colonization of novel habitats by juveniles of the tube-dwelling amphipod Cymadusa filosa associated with the macroalgal host Sargassum filipendula. Methods. We tested the factors listed above on the colonization of juveniles by manipulating natural and artificial plants in both the field and laboratory. Results. In the laboratory, juveniles selected highquality habitats (i.e. natural alga), where both food and shelter are provided, when lowquality resources (i.e. artificial alga) were also available. In contrast, habitat quality and algal patch size did not affect the colonization by juveniles in the field. Finally, the presence of conspecific adults did not affect the colonization of juveniles under laboratory condition but had a weak effect in the field experiment. Our results suggest that $C$. filosa juveniles can select and colonize novel habitats, and that such process can be partially affected by habitat quality, but not by patch size. Also, the presence of conspecifics may affect the colonization by juveniles. Successful colonization by this specific developmental stage under different scenarios indicates that juveniles may act as a dispersal agent in this species. 


\section{Colonization of novel algal habitats by juveniles of a} 2 marine tube-dwelling amphipod

3

4

5 6

7

8

8

9 10

11

12

13

14

(8)

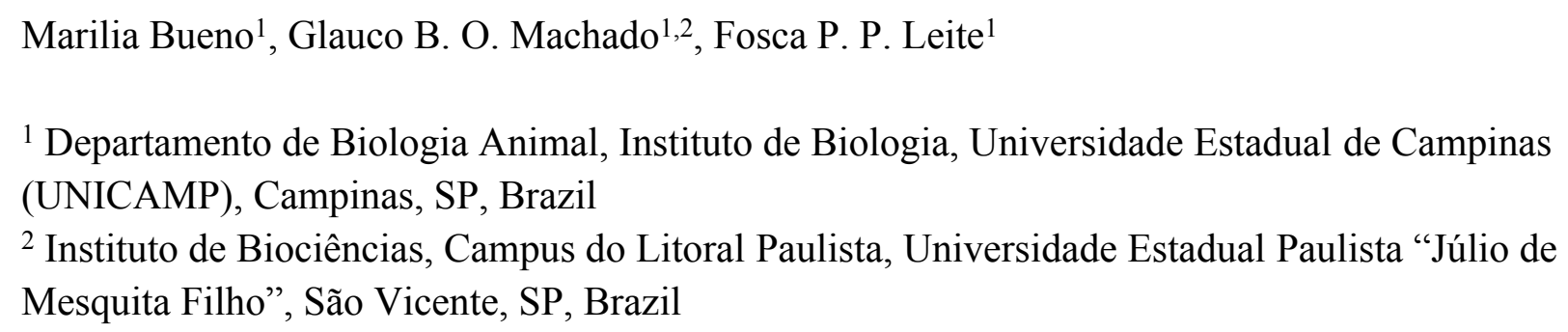




\section{Abstract}

38

67

68

69

70

71

72

73

Background. Dispersal is an important process affecting population dynamics and connectivity. For marine direct developers, both adults and juveniles may disperse. Although the distribution of juveniles can be initially constrained by their mothers' choice, they may be able to leave the parental habitat and colonize other habitats. We investigated the effect of habitat quality, patch size and presence of conspecific adults on the colonization of novel habitats by juveniles of the tube-dwelling amphipod Cymadusa filosa associated with the macroalgal host Sargassum filipendula.

Methods. We tested the factors listed above on the colonization of juveniles by manipulating natural and artificial plants in both the field and laboratory.

Results. In the laboratory, juveniles selected high-quality habitats (i.e. natural alga), where both food and shelter are provided, when low-quality resources (i.e. artificial alga) were also available. In contrast, habitat quality and algal patch size did not affect the colonization by juveniles in the field. Finally, the presence of conspecific adults did not affect the colonization of juveniles under laboratory condition but had a weak effect in the field experiment. Our results suggest that $C$. filosa juveniles can select and colonize novel habitats, and that such process can be partially affected by habitat quality, but not by patch size. Also, the presence of conspecifics may affect the colonization by juveniles. Successful colonization by this specific developmental stage under different scenarios indicates that juveniles may act as a dispersal agent in this species.

6

7




\section{Introduction}

75 Dispersal of individuals has important consequences for population dynamics, connectivity

76

77

78

79

80

81

82

83

84

85

86

87

88

89

90

91

92

93

94

95

96

97

98

99

100

101

102

103

104

105

106

107

108

109

110

111

112

113
(Hansson, 1991; Ronce, 2007; White et al., 2019) and ecosystem function in aquatic environments (Little et al., 2019). This process has been related to ultimate and proximate causes (Bowler \& Benton, 2005; Burgess et al., 2016), and also depends on organismal traits that often vary among individuals within a population, such as body size, sex, and developmental stage (Lawrence, 1987; Munguia et al., 2007; Munguia, 2015). A variety of strategies related to dispersal are found among aquatic invertebrates, involving passive and/or active components and allowing the movement of these organisms across short and long distances (Martel \& Chia, 1991; Palmer et al., 1996; Kinlan \& Gaines, 2003; Ptatscheck, 2020).

For many sessile and mobile benthic species, planktonic larvae represent the main dispersal stage, often exploiting resources in a habitat different from where adults are established (Mileikovsky, 1972; Grantham et al., 2003; Gaines et al., 2007; Weersing \& Toonen, 2009). However, dispersal during other life stages may have important implications for population dynamics (D 'Aloia et al., 2017), with juveniles and/or adults playing important roles on the dispersal process. For mobile benthic species with direct development (i.e. lacking a larval stage), such as amphipods and isopods, transport movements occur over both short and long distances during the whole lifespan (Waage-Nielsen et al., 2003; Kumagai, 2006; Davidson et $a l ., 2008)$. In this case, the spatial distribution of newborn juveniles can be initially constrained by the female's habitat choice (Poore \& Steinberg, 1999), with individuals of different developmental stages often sharing the same habitat (Thiel, 1999; Brooks \& Bell, 2001; Poore, 2004; Miranda \& Thiel, 2008).

The potential dispersal of direct developers may vary with age, with drastic consequences for population dynamics (Munguia et al., 2007; Bringloe et al., 2013). For some species, adults have an important role on the dispersal process, while juveniles can be the main dispersal stage for other direct developers (Franz \& Mohamed, 1989; Bueno \& Leite, 2019). Even when both developmental stages can disperse, adults and juveniles may be under different pressures to emigrate and colonize new patches (DeWitt, 1987; Poore, 2004). For instance, adults may be motivated to disperse in order to find mates to copulate (Bringloe et al., 2013) whereas distribution and dispersal of juveniles may be strongly affected by intraspecific competitive interactions. The presence of conspecifics in a patch may be indicative of habitat quality, attracting juveniles to settle (Bringloe et al., 2013; Drolet et al., 2013); alternatively, the highdensity of conspecific adults can inhibit the settlement of juveniles (Wilson, 1989; Jensen \& Kristensen, 1990). For some tube-dwelling amphipods, large individuals can also be aggressive towards smaller ones (Connell, 1963; Brawley \& Adey, 1981), probably forcing them to search for new sites (DeWitt, 1987).

Yet, juveniles and adults of brooding invertebrates may differ in their ability to exploit habitats with different qualities, resulting in distinct patterns of colonization among these developmental stages. For example, juveniles of the herbivorous amphipod Sunamphitoe parmerong (formerly Peramphithoe parmerong) mainly inhabit the high-quality algal food Sargassum linearifolium, 
114 while adults are able to occupy that host and also to colonize the poor-quality algal food Padina

115

116

117

118

119

120

121

122

123

124

125

126

127

128

129

130

131

132

133

134

135

136

137

138

139

140

141

142

143

144

145

146

147

\section{8}

149

150

151

152

153

crassa (Poore, 2004). Juveniles of the amphipod Pontogammarus robustoides consistently prefer inhabiting natural macrophytes over artificial ones, while adults do not distinguish among these habitat choices (Czarnecka et al., 2010). These examples suggest that the colonization of juveniles may be affected by the habitat quality. Furthermore, large patches can attract more adult amphipods than small ones, while the colonization of juveniles may be unaffected by the patch size, probably because of the small size of these individuals (Bueno \& Leite, 2019). In this sense, understanding the role of dispersal on the population dynamics and connectivity of direct developers requires investigating the factors driving the colonization of specific developmental stages.

Marine macroalgae harbor a diverse fauna in shallow waters (Christie et al., 2009; Gan et al., 2019). Epifaunal assemblages are maintained through the developmental cycle of their hosts, which provide continuous renewal of the resource (i.e. food and/or shelter), allowing associated populations to thrive (Seed \& $O^{\prime}$ Connor, 1981). Among mobile epifauna, amphipods are highly abundant on macroalgal beds and can show colonization within few days on defaunated algal thalli (Taylor \& Cole, 1994; Tanaka \& Leite, 2004). We selected that system to investigate the factors driving the colonization of novel habitats by juveniles. For that, we investigated the effect of habitat quality, algal patch size and presence of conspecific adults on the colonization of juveniles of the tube-dwelling amphipod Cymadusa filosa Savigny, 1816 (Amphipoda: Ampithoidae). We used this developmental stage because a previous investigation reported the important role of juveniles on the dispersal of amphipod species in the study system (Bueno \& Leite, 2019). First, by manipulating natural and artificial plants in both laboratory and field, we tested if juveniles are able to select and colonize a new algal patch depending on the habitat quality. Because juveniles seem to be sensitive to the habitat quality (e.g. Poore, 2004; Czarnecka et al., 2010), we hypothesized that they would colonize high-quality habitats more frequently than low-quality habitats. Second, we tested if the algal patch size affects the colonization rate by juveniles in the field. Because of their small body size, we expected that juveniles would be indifferent to the algal patch size. Finally, under laboratory and field conditions, we tested if the presence of conspecific adults on algal patches affects the settlement of juveniles. We expected that colonization by juveniles would be negatively affected by the presence of adults as a result of intraspecific aggressive interactions (Connell, 1963; Brawley \& Adey, 1981).

\section{Materials \& Methods}

Organisms and study area

The tube-dwelling amphipod Cymadusa filosa is a mesograzer commonly found in association with a variety of macroalgae in marine shallow waters (Tanaka \& Leite, 2003; Appadoo \& Myers, 2004; Bueno et al., 2017; Machado et al., 2019). As a generalist herbivore, C. filosa is able to feed and survive on different algal diets (Machado et al., 2017; 2019). This mesograzer

Peer) reviewing PDF | (2020:08:51640:1:0:NEW 17 Sep 2020) 
154

155

156

157

158

159

160

161

162

163

164

165

166

167

168

169

170

171

172

173

174

175

176

177

178

179

180

181

182

183

184

185

186

187

188

189

190

191

192

193

often builds tubes on algal blades, with newborn juveniles settling in the vicinity of their mother's tube (Appadoo \& Myers, 2003). Organisms used in the field and laboratory experiments were collected on a rocky shore (depth of 1-2 m) at Fortaleza Beach (233' $\mathrm{S}$, $45^{\circ} 10^{\prime} \mathrm{W}$ ), Ubatuba, São Paulo State, Brazil (SISBIO/ICMBio \# 51999-1). The brown alga Sargassum filipendula is abundant on the subtidal level of this rocky shore and shelters a highly diverse amphipod assemblage, including C. filosa (Jacobucci et al., 2009).

\section{Experiments: general procedures}

Field experiments were conducted during March 2017 (late summer). Natural Sargassum thalli used in the experiments were collected at the study area and cleaned of epibionts in the laboratory. For all field experiments, each experimental unit (EU) included one $70 \mathrm{~cm}$ iron stake ( $6 \mathrm{~mm}$ diameter) driven into the sediment to serve as a foundation for the whole unit. A squared plastic screen $(8 \mathrm{~cm}$ X $8 \mathrm{~cm})$ with $1 \mathrm{~cm}$ mesh size was attached to the iron stake with a long zip tie; it supported the algal patch, which was artificial or natural, according to the experiment. A small float was attached to the iron stick and the squared plastic screen by a rope to hold the whole unit erect (see Fig. 1 and Bueno \& Leite, 2019 for further details). Algal substrates were attached to the plastic screen with nylon wires. We randomly deployed EUs parallel to shore $\sim 1$ $\mathrm{m}$ from the shoreline, leaving at least $2 \mathrm{~m}$ spacing between adjacent EUs. After $48 \mathrm{~h}$, experimental algal thalli were placed in bags with mesh size of $200 \mu \mathrm{m}$, transported to the laboratory and frozen. In the laboratory, samples were washed under freshwater to separate amphipods, which were preserved in ethanol $70 \%$, counted under a stereomicroscope and identified to species level according to the literature (i.e., Ruffo, 1982; Barnard \& Karaman, 1991; LeCroy, 2000; LeCroy, 2002; LeCroy, 2004; LeCroy, 2007; LeCroy, 2011).

All laboratory experiments were performed in a climate-controlled room at $22^{\circ} \mathrm{C}$ using a $12: 12 \mathrm{~h}$ photoperiod. Cymadusa filosa individuals were obtained from macroalgal hosts from the study area and, eventually, from other rocky shores nearby. After collection, epiphytes and associated fauna were carefully removed from algal fronds in the laboratory. Cymadusa individuals were kept in a stock culture ( $20 \mathrm{~L}$ plastic tank) with seawater and continuous aeration. We fed amphipods with fresh Sargassum every other day and changed the water once a week. For each experiment, juveniles were obtained from ovigerous females collected in the stock culture. Each replicate (a $20 \mathrm{~L}$ plastic tank with aerated seawater and algal thallus) was conducted with juveniles obtained from the same female. Ideally, the experiments should be conducted with females carrying juveniles in their marsupium, which would be released on the experimental habitats. However, incubation period is variable among females and juveniles can leave the marsupium at different times (Sheader \& Chia, 1970). In this case, we attempted to minimize the difference in the size and age of juveniles within and among replicates by conducting the trials with the smallest individuals on the third day after the female had molted. For that, each ovigerous female was kept in a beaker with seawater $(150 \mathrm{ml})$ until juveniles were released from the female's brood pouch (i.e. after the ovigerous female had molted). Then, newborn juveniles were assigned to a replicate.

Peer) reviewing PDF | (2020:08:51640:1:0:NEW 17 Sep 2020) 
194

195

196

197

198

199

200

201

202

203

204

205

206

207

208

209

210

211

212

213

214

215

216

217

218

219

220

221

222

223

224

225

226

227

228

229

230

231

232

233

Habitat quality

Field and laboratory experiments were conducted to test the effect of habitat quality on the colonization of $C$. filosa juveniles. For that, we used natural Sargassum thalli as high-quality habitat, because it offers both food and shelter for C. filosa (Machado et al., 2019), and artificial Sargassum thalli as low-quality habitat, because it could provide only a shelter for these herbivorous juveniles. Artificial Sargassum fronds (Bio Models Co.) were physically identical to Sargassum thalli in shape, size, branching and color and were arranged to have similar surface area to the natural algae. We estimated algal surface area by measuring the area of flattened branches with transparent adhesive tape in a PVC plate. We used the software Image-J to calculate area and duplicated the values to account for the front and back of branches. In the field, artificial $\left(108.2 \pm 3.0 \mathrm{~cm}^{2}\right)$ and natural $\left(115.8 \pm 25.8 \mathrm{~cm}^{2}\right)$ algae were attached to the squared plastic screen of the experimental structures $(\mathrm{N}=5)$. No difference in area was detected among artificial and natural algae (GLM, Gamma distribution, $\mathrm{P}=0.518$ ). The field experiment was performed as described above in general procedures. The number of C. filosa juveniles on each experimental algal thallus was used as the response variable.

In the laboratory, besides manipulating the quality of the novel habitat, we also manipulated the quality of the source habitat (i.e. the habitat where juveniles were before the novel habitat was offered). For that, we used four levels of combination of source/novel habitats: natural/natural, natural/artificial, artificial/natural and artificial/artificial $(\mathrm{N}=6)$. For each replicate, we placed the first algal thallus (i.e. source habitat) in a $20 \mathrm{~L}$ plastic tank with aerated seawater and added the juveniles using a pipette. After $30 \mathrm{~min}$ of acclimatization, we added the second algal thallus (i.e. novel habitat). Both algal thalli were kept $5 \mathrm{~cm}$ apart and hold erect by using a fishing buoy at the top and a fishing rod at the bottom, both tied with nylon wires. We used similar number of juveniles in each replicate ( $18 \pm 2$ juveniles) to avoid confounding density-related factors. We counted the juveniles on each algal thallus after $24 \mathrm{~h}$ by carefully removing the algal fronds from the tank. We then calculated the proportion of juveniles that colonized the novel habitat (i.e. response variable). After each experimental run, we filtered all the water from the tanks and cleaned the algal fronds to ensure that there were no remaining juveniles.

Algal patch size

A field experiment was performed to test the effect of algal patch size on the colonization of $C$. filosa juveniles. For that, the experiment consisted of two treatments representing algae with small $\left(30.8 \pm 13.8 \mathrm{~cm}^{2}\right)$ and large $\left(115.8 \pm 25.8 \mathrm{~cm}^{2}\right)$ surface area $(\mathrm{N}=5)$. Sargassum fronds with small and large surface area without any epibionts were attached to the square plastic screen on the experimental structures in the field, then the experiment was conducted as described above. The number of $C$. filosa juveniles on each experimental algal thallus was used as response variable. We estimated algal surface area applying the same methodology described above.

Presence of conspecific adults

Peer] reviewing PDF | (2020:08:51640:1:0:NEW 17 Sep 2020) 
234 To test the effect of conspecific adults on colonization by C. filosa juveniles, we performed field

235

236

237

238

239

240

241

242

243

244

245

246

247

248

249

250

251

252

253

254

255

256

257

258

259

260

261

262

263

264

265

266

267

268

269

270

271

272

273

and laboratory experiments manipulating the abundance of adults on algal thalli. In both experiments, we used only male adults to avoid mating between males and females. For the field experiment, to test how the presence of $C$. filosa adults affects juveniles' colonization, we kept the algal thallus with adults inside of a $250 \mathrm{ml}$ acrylic cup. We perforated the walls and the lid of the acrylic cups using a drill with a fine bit, producing $1 \mathrm{~mm}$ diameter orifices. The orifices allowed water and juveniles to pass (and perhaps small adults). In a laboratory pilot trial, we confirmed that C. filosa juveniles were able to pass through the wall of the cup through the orifices. To allow adult males to build tubes and settle in the Sargassum fronds, we kept them in cups with seawater and algal patches for $24 \mathrm{~h}$ in the laboratory before beginning the field experiment. Each experimental set was composed of one algal patch ( $\sim 3.6 \mathrm{~g}$ of wet mass) with 0,4 or 8 adult males within an acrylic cup $(\mathrm{N}=4$ or $\mathrm{N}=5)$. We attached each experimental set to the squared plastic screens of the experimental structures in the field. The experiment was performed using the same methods described above. After the collection, experimental sets were transported to the laboratory and, before freezing these samples, cups were inspected for the presence of live C. filosa adults to assess if the number of active adult males inside the cups had changed throughout the experiment. After $48 \mathrm{~h}$, for the treatments with 0,4 and 8 male adults added initially, we found an average of 0, $3.6( \pm 0.5)$ and $7.5( \pm 0.6)$ adults inside the cups, respectively. As a response variable, we used the number of $C$. filos $a$ juveniles in each experimental set.

In the laboratory, we tested whether the effect of adults on the colonization of natural algal patches by juveniles depends on the type of source habitat occupied by juveniles. For that, we manipulated the presence of adults on natural algal thallus (two levels: 0 or 4 adults) and the type of source habitat of juveniles (three levels: no algal thallus, artificial algal thallus and natural algal thallus) in an orthogonal design ( $\mathrm{N}=6$ for each level of combination). Considering in the field experiment there was no difference for both treatments with adults regarding their effects on juveniles' colonization (see Results), we decided to use only two levels for adult presence (i.e. 0 and 4 adults). Each replicate consisted of one plastic tank with a natural Sargassum patch with or without adult males. Cymadusa adult males ( $15.7 \pm 1.6 \mathrm{~mm}$ of body size) were obtained from the stock culture, carefully placed on the algal frond using a delicate paintbrush and kept in the plastic tank for at least $6 \mathrm{~h}$ for acclimatization. Again, we used a similar number of juveniles in each replicate ( $16 \pm 2$ juveniles) to avoid confounding density-related factors. Juveniles were added to perforated acrylic cups similar to those used in the field experiment, placed on one of the types of source habitat. The cup with the juveniles was $5 \mathrm{~cm}$ away from the natural algal thallus with or without adults. After $24 \mathrm{~h}$, we counted the number of juveniles and then calculated the proportion of juveniles that colonized the algal thalli outside the cups.

Data analyses

We used general linear models (GLM) to analyze data from field and laboratory experiments. To compare the abundance of $C$. filos a juveniles among treatments of the field

Peer) reviewing PDF | (2020:08:51640:1:0:NEW 17 Sep 2020) 
274 experiments, we used GLM with Poisson ('habitat quality' experiment), Quasi-poisson ('algal 275 patch size' experiment) or Negative binomial ('presence of adults' experiment) distributions. For 276 the field experiment testing the effect of presence of adults, algal wet mass (log-transformed) 277 was used as an offset variable. For the laboratory experiments, we compared the proportion of

278

279 280 281

282

283

284

285

286

287

288

289

290

291

292

293

294

295

296

297

298

299

300

301

302

303

304

305

306

307

308

309

310

311

312

313 juveniles that colonized a novel habitat among treatments using GLM with Quasi-binomial distribution. When the effect of a factor was detected, we used Tukey's test to explore possible differences among treatments.

\section{Results}

Habitat quality

A total of 37 juvenile amphipods colonized experimental algal thalli in the field. From this, 17 juveniles were identified as $C$. filosa. Although more individuals were found in natural algal patches, there was no difference in the abundance of $C$. filosa juveniles between artificial (1.2 \pm 0.8 juveniles) and natural (2.2 \pm 1.3 juveniles) algal thalli (GLM, Poisson distribution, $\mathrm{P}=$ 0.222). In contrast, in the laboratory experiment, the quality of source and novel habitats (i.e. artificial or natural alga) influenced the colonization rate by C. filosa juveniles (GLM, Quasibinomial distribution, $\mathrm{P}<0.001$ ). The highest proportion of juveniles colonizing a novel habitat was found when the source was artificial, and the novel habitat was natural alga. In turn, the lowest proportion of juveniles colonizing a novel habitat occurred when the source and novel habitats were a natural and an artificial alga, respectively. Intermediate values of proportion of juveniles colonizing a novel habitat were found when novel and source habitats were of the same quality (Fig. 2).

Algal patch size

Of 47 juvenile amphipods that colonized the experimental algal thalli, 12 were C. filosa juveniles. The abundance of $C$. filosa juveniles was similar between algal patches with small (1.2 \pm 1.3 juveniles) and large (2.2 \pm 1.3 juveniles) surface area (GLM, Quasi-poisson distribution, $\mathrm{P}=0.277)$.

Presence of adults

In the field experiment, 111 C. filosa juveniles (of 313 juvenile amphipods in total) colonized experimental algal thalli. Overall, the abundance of $C$. filosa juveniles had a tendency to increase with the density of adults (Fig. 3). However, this effect was only marginally significant (GLM, Negative binomial distribution, $\mathrm{P}=0.055$ ). For the laboratory experiment, we found a significant interaction between the factors 'presence of adults' and 'type of source habitat' (Table 1). Despite this, from the Tukey's test, we found that differences (or similarities) among levels of one factor did not depend on the levels of the other factor for the meaningful comparisons to this study. Cymadusa filosa juveniles without alga or with artificial alga colonized a novel habitat (with or without adults) in a higher proportion than juveniles with natural alga as source habitat 
314 (Fig. 4). Within each level of source habitat, the presence of adults did not affect the colonization 315 by juveniles (Fig. 4).

316

317

\section{Discussion}

319

320

321

322

323

324

325

326

327

328

329

330

331

332

333

334

335

336

337

338

339

340

341

342

343

344

345

346

347

348

349

350

351

352

353

Habitat quality does not seem to affect colonization by juveniles of Cymadusa filosa on a local scale and under natural conditions (i.e. field experiment). However, on a smaller scale under controlled conditions (i.e. laboratory experiment), juveniles are able to optimize their habitat choice by selecting a high-quality resource (i.e. natural alga), where both food and shelter are provided, when low-quality resource (i.e. artificial alga) is available as a source or novel habitat. The colonization by juveniles did not depend on the algal patch size. The presence of conspecific adults does not affect the colonization of juveniles under controlled conditions but may be important under natural conditions. These findings suggest that, although very initially constrained by their mothers' choice, $C$. filosa juveniles can rapidly search, choose and colonize novel habitats, corroborating their previously reported dispersive potential (Bueno \& Leite, 2019), and that such process can be partially affected by the habitat quality.

In the laboratory, juveniles showed high colonization rates when going from artificial source habitats to natural novel habitats. In contrast, the lowest colonization rates were found when an artificial algal thallus was offered (i.e. novel habitat) for juveniles inhabiting a natural alga. In accordance, intermediate colonization rates were found when source and novel habitats were similar (i.e. both were natural or artificial algal thalli). These results suggest that $C$. filosa juveniles have a tendency to stay where they are, as expected since they are released from the mother brood pouch, unless a better-quality resource is available, corroborating the low mobility behavior often observed for tube-building amphipods (Duffy \& Hay, 1994; Poore \& Steinberg, 1999). Similar results were found in the laboratory experiment testing the effect of adult's presence. In this case, natural algal thalli (with or without adults) were offered as novel habitat in all treatments and juveniles with an artificial alga or without any alga (i.e. low-quality source habitats) showed higher colonization rates than those with a natural alga as source habitat. In this sense, our results corroborate the idea that the distribution of juvenile amphipods living on macroalgae is not restricted by the females' choice (Poore, 2005; Bueno \& Leite, 2019) and that their colonization process is partially motivated by the habitat quality (Poore, 2004). Sargassum is a high-quality food for $C$. filosa and, thus, is not only used for shelter by this herbivorous amphipod (Machado et al., 2017; 2019). This role for Sargassum is supported by our results from laboratory experiments with artificial and natural algal thalli. Also, these results suggest that $C$. filosa juveniles can detect a suitable host to colonize. Similarly, the tube-building amphipod Jassa herdmani can discriminate between its host hydrozoan Tubularia indivisa and other artificial substrates, indicating this species may have a detection mechanism, although it is not fully understood (Havermans et al., 2007). Moreover, the amphipod Incisocalliope symbioticus seems to use chemical cues to locate and colonize its host, the gorgonian octocoral Melithaea flabellifera, at short distances (Kumagai, 2006). Chemical cues from Sargassum may

Peer) reviewing PDF | (2020:08:51640:1:0:NEW 17 Sep 2020) 
354 be an important mechanism for C. filosa juveniles detect a suitable and high-quality habitat and

355

356

357

358

359

360

361

362

363

364

365

366

367

368

369

370

371

372

373

374

375

376

377

378

379

380

381

382

383

384

385

386

387

388

389

390

391

392

further studies are required to elucidate it.

The ability to detect and colonize a suitable habitat should be advantageous for C. filosa

juveniles when (1) there is a mismatch between feeding (or habitat) preference of adults and performance of juveniles (e.g. Cruz-Rivera \& Hay, 2001; McDonald \& Bingham, 2010) and/or (2) the abundance of adults on high-quality food algae is constrained by extrinsic factors to the host, such as predation and wave action (e.g. Sotka, 2007; Lasley-Rasher et al., 2011; Machado et al., 2019). The feeding behavior and its consequences for the survival, growth and reproduction of $C$. filos $a$ are tightly linked, with adults preferring algal hosts that results in the highest performance of juveniles (Machado et al., 2017; 2019). However, in the study area, $C$. filosa has been found on the red alga Dichotomaria marginata, which is a poor-quality food, in densities higher than on the high-quality food Sargassum filipendula (Machado et al., 2019), suggesting a trade-off between food and shelter for this herbivorous amphipod. In this context, the ability of $C$. filosa juveniles to detect and colonize novel and suitable habitats, regardless their mothers' choice, should be advantageous for the success of this developmental stage and, consequently, for the species.

Contrasting with our expectations and the results from the laboratory experiments, we did not find any effect of habitat quality on juveniles' colonization in the field experiment, suggesting other factors may influence the colonization of these amphipods under natural conditions. The similar abundance of C. filosa juveniles on artificial and natural algal thalli may suggest that the algal morphology per se has an important role regarding the host use by this amphipod in the field. Algal morphology mediates the vulnerability of associated fauna to predation (Zamzow et al., 2010; Ware et al., 2019). Also, structural and spatial traits of macroalgae affects the availability of space for the epifauna (Hacker \& Steneck, 1990; Carvalho et al., 2018). The colonization of artificial substrates mimicking natural plants by epifaunal species highlights the importance of the physical structure of macrophytes for the settlement of associated fauna (Virnstein \& Curran, 1986; Norderhaug et al., 2002; Waage-Nielsen et al., 2003). Because artificial algal thalli in the field were rapidly colonized by juvenile amphipods, it is probably functioning as a suitable shelter, at least temporarily.

The size of algal thalli available for colonization in the field experiment did not affect the number of $C$. filosa juveniles found on these substrates. In a previous laboratory experiment, $C$. filosa juveniles colonized small and large algal patches in similar proportions (Bueno \& Leite, 2019). The availability of substrate is often related to the habitat complexity, thus is an important factor for the association of mobile fauna with macrophytes (Stoner, 1980; Hacker \& Steneck, 1990). For instance, as the surface area of a substrate increase, it can decrease the vulnerability of mobile fauna to predation (Russo, 1987). However, prey size may also mediate the intensity of predation on amphipods. Predators may preferentially consume larger individuals (e.g. Sturaro et al., 2016) while smaller animals may be less vulnerable to detection and consumption by predators (Schlacher \& Wooldridge, 1996). In this sense, although habitat size is important for

Peer) reviewing PDF | (2020:08:51640:1:0:NEW 17 Sep 2020) 
393

394

395

396

397

398

399

400

401

402

403

404

405

406

407

408

409

410

411

412

413

414

415

416

417

418

419

420

421

422

423

424

425

426

427

428

429

430

431

432

the associated fauna, the surface area may be less crucial for the colonization of a Sargassum thallus by small bodied organisms, such as $C$. filosa juveniles.

No effect of the presence of conspecific adults on the colonization of $C$. filosa juveniles was detected in the laboratory experiment. In contrast, we found a marginally significant trend of juveniles' abundance increasing with adult density. The effects of conspecifics on the recruitment and settlement of juvenile amphipods are variable. The presence of adults does not affect the habitat choice of juveniles of the amphipod Pontogammarus robustoides (Czarnecka et al., 2010). For the tube-dwelling amphipod Corophium volutator, high densities of adults may negatively affect the settlement of conspecific juveniles, as a result of intraspecific competition (Wilson, 1989; Jensen \& Kristensen, 1990). The effects of intraspecific competition depend on the density of conspecifics and food concentration (Hill, 1992; Wenngren \& Ólafsson, 2002; Van Tomme et al., 2012). In our field experiment, we used treatments with adults in densities (from $\sim 1$ to $2 \mathrm{ind} / \mathrm{g}$ of alga) that were much higher than that previously reported for $C$. filos $a$ at same study site ( $0.2 \mathrm{ind} / \mathrm{g}$ of alga; see Machado et al., 2019). Yet, the presence of adult conspecifics on algal patches did not negatively affect juveniles' colonization, suggesting that intraspecific competition for food and/or space is not an important factor for the colonization of C. filosa juveniles. In contrast, it is possible that $C$. filosa juveniles are attracted by the presence of adults, which could explain the increase of juveniles on intertidal soft-bottom habitats, which could be an indicative of habitat quality (Bringloe et al., 2013; Drolet et al., 2013). Further experiments with higher replication are necessary to confirm this hypothesis for $C$. filosa juveniles.

\section{Conclusions}

By combining laboratory and field experiments, we found that the colonization of novel habitats by $C$. filosa juveniles can be affected by the habitat quality, but not by the patch size. Also, the presence of conspecifics may affect the colonization by juveniles. Contrasting results between laboratory and field experiments manipulating the habitat quality and the presence of conspecifics highlighted the importance of using different approaches to better understand the factors determining the host use by juvenile amphipods. In the present study, we used artificial algal thalli as a low-quality habitat; it would be interesting to investigate the behavior of $C$. filosa juveniles when they have more than one macroalgal host to select, since in the shallow subtidal areas they have a variety of biological substrates available for colonization ( Appadoo \& Myers, 2004; Bueno et al., 2017; Machado et al., 2019). Investigating dispersal patterns during specific life stages can greatly contribute to understand the movement paths during the lifespan of organisms (Allen et al., 2018). After dispersing, the colonization of new substrates will set the distribution of populations among hosts (Poore, 2005; Chapman, 2007), contributing to the maintenance of populations at local and regional scales.

\section{Acknowledgements}


433 We thank Ana P. Ferreira and Ricardo Ota for the assistance with field and laboratory work, and 434 Edson A. Vieira for valuable comments.

435

436

437

438

439

440

441

442

443

444

445

446

447

448

449

450

451

452

453

454

455

456

457

458

459

460

461

462

463

464

465

466

467

468

469

470

471

472

\section{References}

Allen RM, Metaxas A, Snelgrove PVR. 2018. Applying movement ecology to marine animals with complex life cycles. Annual Review of Marine Science 10: 19-42.

Appadoo C, Myers AA. 2003. Observations on the tube-building behaviour of the marine amphipod Cymadusa filosa Savigny (Crustacea: Ampithoidae). Journal of Natural History 37: 2151-2164.

Appadoo C, Myers AA. 2004. Reproductive bionomics and life history traits of three gammaridean amphipods, Cymadusa filosa Savigny, Ampithoe laxipodus Appadoo and Myers and Mallacoota schellenbergi Ledoyer from the tropical Indian Ocean (Mauritius). Acta Oecologica 26: 227-238.

Barnard JL, Karaman G. 1991. The families and genera of marine gammaridean Amphipoda (except marine gammaroids). Records of the Australian Museum Suppl. 13, 1-866.

Bowler DE, Benton TG. 2005. Causes and consequences of animal dispersal strategies: relating individual behaviour to spatial dynamics. Biological Reviews 80: 205-225.

Brawley SH, Adey WH. 1981. The effect of micrograzers on algal community structure in a coral reef microcosm. Marine Biology 61: 167-177.

Bringloe TT, Drolet D, Barbeau MA, Forbes MR, Gerwing TG. 2013. Spatial variation in population structure and its relation to movement and the potential for dispersal in a model intertidal invertebrate. PLoS ONE 8(7): e69091.

Brooks RA, Bell SS. 2001. Colonization of a dynamic substrate: factors influencing recruitment of the wood-boring isopod, Sphaeroma terebrans, onto red mangrove (Rhizophora mangle) prop roots. Oecologia 127: 522-532.

Bueno M, Dias GM, Leite FPP. 2017. The importance of shore height and host identity for amphipod assemblages. Marine Biology Research 13: 870-877.

Bueno M, Leite FPP. 2019. Age and life style affect macroalgae colonization by amphipods in shallow marine environments. Journal of Experimental Marine Biology and Ecology 514515: 59-66.

Burgess SC, Baskett ML, Grosberg RK, Morgan SG, Strathmann RR. 2016. When is dispersal for dispersal? Unifying marine and terrestrial perspectives. Biological Reviews 91:867-882.

Carvalho, NF, Grande H, Rosa Filho JS, Jacobucci GB. 2018. The structure of gammarid amphipod (Crustacea, Peracarida) assemblages associated with Sargassum (Phaeophyta, Fucales) and their link with the structural complexity of algae. Hydrobiologia 820: 245-254.

Chapman MG. 2007. Colonization of novel habitat: Tests of generality of patterns in a diverse invertebrate assemblage. Journal of Experimental Marine Biology and Ecology 348: 97110.Christie H, Norderhaug KM, Fredriksen S. 2009. Macrophytes as habitat for fauna. Marine Ecology Progress Series 396: 221-233. 
473 Connell JH. 1963. Territorial behavior and dispersion in some marine invertebrates. Researches 474 on Population Ecology 5: 87-101.

475 Cruz-Rivera E, Hay ME. 2001. Macroalgal traits and the feeding and fitness of an herbivorous 476 amphipod: the roles of selectivity, mixing, and compensation. Marine Ecology Progress 477 Series 218: 249-266.

478 Czarnecka M, Kobak J, Wiśniewski R. 2010. Preferences of juveniles and adults of the invasive 479 480 481

482 483

484

485

486

487

488

489

490

491

492

493

494

495

496

497

498

499

500

501

502

503

504

505

506

507

508

509

510

511

512 Ponto-Caspian amphipod Pontogammarus robustoides for various species of macrophytes and artificial substrata. Hydrobiologia 655: 79-88.

D'Aloia CC, Daigle RM, Côté IM, Curtis JM, Guichard F, Fortin MJ. 2017. A multiple-species framework for integrating movement processes across life stages into the design of marine protected areas. Biological Conservation 216: 93-100.

Davidson TM, Rumrill SS, Shanks AL. 2008. Colonization and substratum preference of an introduced burrowing crustacean in a temperate estuary. Journal of Experimental Marine Biology and Ecology 354: 144-149.

DeWitt TH. 1987. Microhabitat selection and colonization rates of a benthic amphipod. Marine Ecology Progress Series 36: 237-250.

Drolet D, Coffin MRS, Barbeau MA, Hamilton DJ. 2013. Influence of intra- and interspecific interactions on short-term movement of the amphipod Corophium volutator in varying environmental conditions. Estuaries and Coasts 36: 940-950.

Duffy JE, Hay ME. 1994. Herbivore resistance to seaweed chemical defense: the roles of mobility and predation risk. Ecology 75: 1304-1319.

Franz DR, Mohamed Y. 1989. Short-distance dispersal in a fouling community amphipod crustacean, Jassa marmorata Holmes. Journal of Experimental Marine Biology and Ecology 133: 1-13.

Gaines SD, Gaylord B, Gerber LR, Hastings A, Kinlan BP. 2007. Connecting places: the ecological consequences of dispersal in the sea. Oceanography 20: 90-99.

Gan SX, Tay YC, Huang D (2019). Effects of macroalgal morphology on marine epifaunal diversity. Journal of the Marine Biological Association of the United Kingdom, 99: 16971707. https://doi.org/10.1017/S0025315419000900

Grantham BA, Eckert GL, Shanks AL. 2003. Dispersal potential of marine invertebrates in diverse habitats. Ecological Applications 13: S108-S116.

Hacker SD, Steneck RS. 1990. Habitat architecture and the abundance and body-size dependent habitat selection of a phytal amphipod. Ecology 71: 2269-2285.

Hansson L. 1991. Dispersal and connectivity in metapopulations. Biological Journal of the Linnean Society 42: 89-103.

Havermans C, De Broyer C, Mallefet J, Zintzen V. 2007. Dispersal mechanisms in amphipods: a case study of Jassa herdmani (Crustacea, Amphipoda) in the North Sea. Marine Biology 153: 83-89.

Hill C. 1992. Interactions between year classes in the benthic amphipod Monoporeia affinis: effects on juvenile survival and growth. Oecologia 91: 157-162. 
513 Jacobucci GB, Tanaka MO, Leite FPP. 2009. Temporal variation of amphipod assemblages 514 associated with Sargassum filipendula (Phaeophyta) and its epiphytes in a subtropical shore.

515 Aquatic Ecology 43: 1031-1040.

516 Jensen KT, Kristensen LD. 1990. A field experiment on competition between Corophium

517 volutator (Pallas) and Corophium arenarium Crawford (Crustacea, Amphipoda): effects on

518 survival, reproduction and recruitment. Journal of Experimental Marine Biology and Ecology

519 137: 1-24.

520 Kinlan BP, Gaines SD. 2003. Propagule dispersal in marine and terrestrial environments: a

521 community perspective. Ecology 84: 2007-2020.

522 Kumagai NH. 2006. Distance effects on patterns and processes of dispersal in an octocoral-

523 associated amphipod. Marine Ecology Progress Series 321: 203-214.

524 Lasley-Rasher RS, Rasher DB, Marion ZH, Taylor RB, Hay ME. 2011. Predation constrains host

525

526

527

528

529

530

531

532

533

534

535

536

537

538

539

540

541

542

543

544

545

546

547

548

549

550

551

552

553 choice for a marine mesograzer. Marine Ecology Progress Series 434: 91-99.

Lawrence WS. 1987. Dispersal: an alternative mating tactic conditional on sex ratio and body size. Behavioral Ecology and Sociobiology 21: 367-373.

LeCroy SE. 2000. An Illustrated Identification Guide to the Nearshore Marine and Estuarine Gammaridean Amphipoda of Florida. Volume 1, Families Gammaridae, Hadziidae, Isaeidae, Melitidae and Oedicerotidae. Tallahassee: Florida Department of Environmental Protection.

LeCroy SE. 2002. An Illustrated Identification Guide to the Nearshore Marine and Estuarine Gammaridean Amphipoda of Florida, Volume 2, Families Ampeliscidae, Amphilochidae, Amphithoidae, Aoridae, Argissidae and Haustoriidae. Tallahassee: Florida Department of Environmental Protection.

LeCroy SE. 2004. An Illustrated Identification Guide to the Nearshore Marine and Estuarine Gammaridean Amphipoda of Florida. Volume 3, Families Bateidae, Biancolinidae, Cheluridae, Colomastigidae, Corophidae, Cyproideidae and Dexaminidae. Tallahassee: Florida Department of Environmental Protection.

LeCroy SE. 2007. An Illustrated Identification Guide to the Nearshore Marine and Estuarine Gammaridean Amphipoda of Florida, Volume 4, Families Anamixidae, Eusiridae, Hyalellidae, Hyalidae, Iphimediidae, Ischyroceridae, Lysianassidae, Megaluropidae and Melphidippidae. Tallahassee: Florida Department of Environmental Protection.

LeCroy SE. 2011. An Illustrated Identification Guide to the Nearshore Marine and Estuarine Gammaridean Amphipoda of Florida, Volume 5, Families Leucothoidae, Liljeborgiidae, Neomegamphopidae, Ochlesidae, Phliantidae, Phoxocephalidae, Platyischnopidae, Pleustidae, Podoceridae, Pontoporeiidae, Sebidae, Stenothoidae, Synopiidae and Talitridae. Tallahassee: Florida Department of Environmental Protection.

Little CJ, Fronhofer EA, Altermatt F. 2019. Dispersal syndromes can impact ecosystem functioning in spatially structured freshwater populations. Biology Letters 15: 20180865. http://dx.doi.org/10.1098/rsbl.2018.0865

Machado GBO, Ferreira AP, Leite FPP. 2019. Testing the importance of predation refuge vs. food quality in determining the use of macroalgal hosts by a generalist marine mesograzer. Marine Biology 166: 55. 
554

555

556

557

558

559

560

561

562

563

564

565

566

567

568

569

570

571

572

573

574

575

576

577

578

579

580

581

582

583

584

585

586

587

588

589

590

591

592

Machado GBO, Siqueira SGL, Leite FPP. 2017. Abundance, performance, and feeding preference of herbivorous amphipods associated with a host alga-epiphyte system. Journal of Experimental Marine Biology and Ecology 486: 328-335.

Martel A, Chia F.-S. 1991. Drifting and dispersal of small bivalves and gastropods with direct development. Journal of Experimental Marine Biology and Ecology 150: 131-147.

McDonald PS, Bingham BL. 2010. Comparing macroalgal food and habitat choice in sympatric, tube-building amphipods, Ampithoe lacertosa and Peramphithoe humeralis. Marine Biology 157: 1513-1524.

Mileikovsky SA. 1972. The "Pelagic Larvaton" and its role in the biology of the world ocean, with special reference to pelagic larvae of marine bottom invertebrates. Marine Biology 16: 13-21.

Miranda L, Thiel M. 2008. Active and passive migration in boring isopods Limnoria spp. (Crustacea, Peracarida) from kelp holdfasts. Journal of Sea Research 60: 176-183.

Munguia P. 2015. Role of sources and temporal sinks in a marine amphipod. Biology Letters 11: 20140864.

Munguia P, Mackie C, Levitan DR. 2007. The influence of stage-dependent dispersal on the population dynamics of three amphipod species. Oecologia 153: 533-541.

Norderhaug KM, Christie H, Rinde E. 2002. Colonisation of kelp imitations by epiphyte and holdfast fauna; a study of mobility patterns. Marine Biology 141: 965-973.

Palmer MA, Allan DJ, Butman CA. 1996. Dispersal as a regional process affecting the local dynamics of marine and stream benthic invertebrates. Trends in Ecology and Evolution 11: 322-326.

Poore AGB. 2004. Spatial associations among algae affect host use in a herbivorous marine amphipod. Oecologia 140: 104-112.

Poore AGB. 2005. Scales of dispersal among hosts in a herbivorous marine amphipod. Austral Ecology 30: 219-228.

Poore AGB, Steinberg PD. 1999. Preference-performance relationships and effects of host plant choice in an herbivorous marine amphipod. Ecological Monographs 69: 443-464.

Ptatscheck C, Gansfort B, Majdi N, Traunspurger W. 2020. The influence of environmental and spatial factors on benthic invertebrate metacommunities differing in size and dispersal mode. Aquatic Ecoloy 54: 447-461. https://doi.org/10.1007/s10452-020-09752-2

Ronce O. 2007. How does it feel to be like a rolling stone? Ten questions about dispersal evolution. Annual Review of Ecology, Evolution, and Systematics 38: 231-253.

Ruffo S. 1982. The Amphipoda of the Mediterranean, Part 1, 2 and 3, Gammaridea (Acanthonozomatidae to Gammaridae). Mémoires de l'Institut Océanographique, Monaco.

Russo AR. 1987. Role of habitat complexity in mediating predation by the gray damselfish Abudefduf sordidus on epiphytal amphipods. Marine Ecology Progress Series 36: 101-105. Schlacher TA, Wooldridge TH. 1996. Patterns of selective predation by juvenile, benthivorous fish on estuarine fauna. Marine Biology 125: 241-247. 
593 Seed R, O'Connor RJ. 1981. Community organization in marine algal epifaunas. Annual Review

594

595

596

597

598

599

600

601

602

603

604

605

606

607

608

609

610

611

612

613

614

615

616

617

618

619

620

621

622

623

624

625

626

627

628

629

630

631

632 of Ecology and Systematics 12: 49-74.

Sheader M, Chia, F-S. 1970. Development, fecundity and brooding behaviour of the amphipod, Marinogammarus obtusatus. Journal of the Marine Biological Association of the United Kingdom 50: 1079-1099.

Sotka EE. 2007. Restricted host use by the herbivorous amphipod Peramphithoe tea is motivated by food quality and abiotic refuge. Marine Biology 151: 1831-1838.

Stoner AW. 1980. Perception and choice of substratum by epifaunal amphipods associated with seagrasses. Marine Ecology Progress Series 3: 105-111. Sturaro N, Gobert S, Pérez-Perera A, Caut S, Panzalis P, Navone A, Lepoint G. 2016. Effects of fish predation on Posidonia oceanica amphipod assemblages. Marine Biology 163, 58. doi:10.1007/s00227-016-2830-1

Tanaka MO, Leite FPP. 2003. Spatial scaling in the distribution of macrofauna associated with Sargassum stenophyllum (Mertens) Martius: analyses of faunal groups, gammarid life habits, and assemblage structure. Journal of Experimental Marine Biology and Ecology 293: 1-22.

Tanaka MO, Leite FPP. 2004. Distance effects on short-term recolonization of Sargassum stenophyllum by mobile epifauna, with an analysis of gammarid life habits. Journal of the Marine Biological Association of the United Kingdom 84: 901-910.

Taylor RB, Cole RG. 1994. Mobile epifauna on subtidal brown seaweeds in northeastern New Zealand. Marine Ecology Progress Series 115: 271-282.

Thiel M. 1999. Host-use and population demographics of the ascidian-dwelling amphipod Leucothoe spinicarpa: indication for extended parental care and advanced social behaviour. Journal of Natural History 33: 193-206.

Van Tomme J, Van Colen C, Degraer S, Vincx M. 2012. Encounter competition partly explains the segregation of the sandy beach amphipods Bathyporeia pilosa and Bathyporeia sarsi. A mesocosm experiment. Journal of Experimental Marine Biology and Ecology 438: 118-124.

Virnstein RW, Curran MC. 1986. Colonization of artificial seagrass versus time and distance from source. Marine Ecology Progress Series 29: 279-288.

Waage-Nielsen E, Christie H, Rinde E. 2003. Short-term dispersal of kelp fauna to cleared (kelpharvested) areas. Hydrobiologia 503: 77-91.

Ware C, Dijkstra JA, Mello K, Stevens A, O'Brien B, Ikedo W (2019) A novel threedimensional analysis of functional architecture that describes the properties of macroalgae as a refuge. Mar Ecol Prog Ser 608:93-103. https://doi.org/10.3354/meps12800

Weersing K, Toonen RJ. 2009. Population genetics, larval dispersal, and connectivity in marine systems. Marine Ecology Progress Series 393: 1-12.

Wenngren J, Ólafsson E. 2002. Intraspecific competition for food within and between year classes in the deposit-feeding amphipod Monoporeia affinis - the cause of population fluctuations? Marine Ecology Progress Series 240: 205-213.

White JW, Carr MH, Caselle JE, Washburn L, Woodson CB, Palumbi SR, Carlson PM, Warner RR, Menge BA, Barth JA, Blanchette CA, Raimondi PT, Milligan K. 2019. Connectivity, dispersal, and recruitment: Connecting benthic communities and the coastal ocean. 
633 Oceanography 32: 50-59, https://doi.org/10.5670/oceanog.2019.310Wilson WH. 1989.

634 Predation and the mediation of intraspecific competition in an infaunal community in the Bay 635 of Fundy. Journal of Experimental Marine Biology and Ecology 132: 221-245.

636 Zamzow JP, Amsler CD, McClintock JB, Baker BJ. 2010. Habitat choice and predator avoidance 637 by Antarctic amphipods: the roles of algal chemistry and morphology. Marine Ecology

638 Progress Series 400: 155-163.

639

640

641

642

643

644

645

646

647

648

649

650

651

652

653

654

655

656

657

658

659

660

661

662

663

664

665

666

667

668

669

670

671

672 
673 Figure captions

674

675 Figure 1. General scheme of the experimental unit used in field experiments. From Bueno and 676 Leite, 2019.

677

678 Figure 2. Proportion of Cymadusa filosa juveniles colonizing the novel habitat offered in the 679 laboratory. Source and novel habitats are indicated as "nat" when natural alga and as "art" when 680 artificial alga. Arrows indicate the colonization path. Bars represent standard error. Different 681 letters indicate significant difference among combinations of source and novel habitats (Tukey 682 test, $\mathrm{p}<0.05)$.

683

684 Figure 3. Abundance of juveniles of Cymadusa filosa that colonized algal experimental patches 685 in the field. Different numbers of conspecific adult males (0, 4 and 8$)$ were established in the 686 algal patches when they were deployed in the field. Bars represent standard error.

687

688

689 Figure 4. Proportion of juveniles of Cymadusa filosa colonizing the novel habitat (natural alga 690 with or without adults) when different source habitats (natural algal thallus, artificial algal and 691 none) were provided to the juveniles in the laboratory. Bars represent standard error. Different 692 letters indicate significant difference among juveniles' source habitats (Tukey test, $\mathrm{p}<0.05$ ).

693

694

695

696

697 
Figure 1

General scheme of the experimental unit used in field experiments. From Bueno and Leite, 2019. 


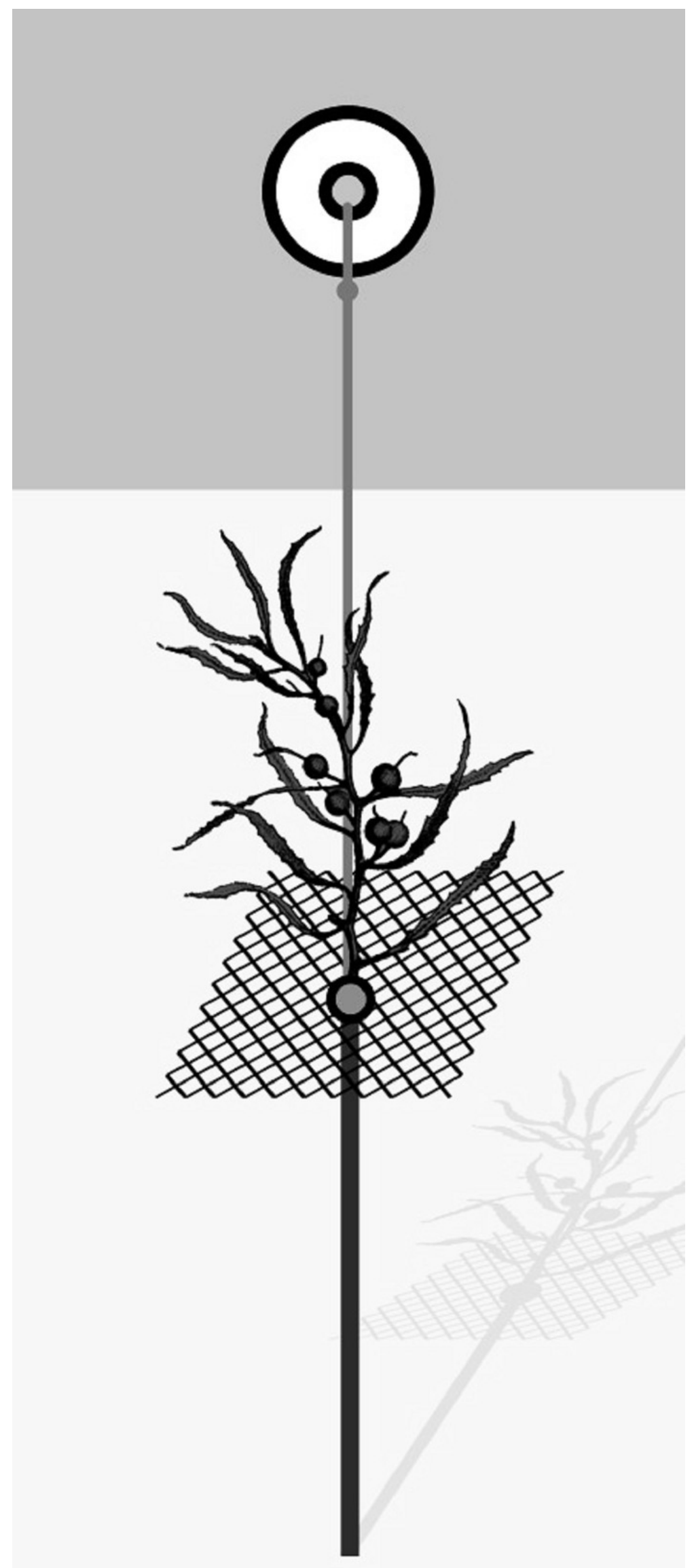


Figure 2

Proportion of Cymadusa filosa juveniles colonizing the novel habitat offered in the laboratory. Source and novel habitats are indicated as "nat" when natural alga and as "art" when artificial alga. Arrows indicate the colonization path. Bars represe

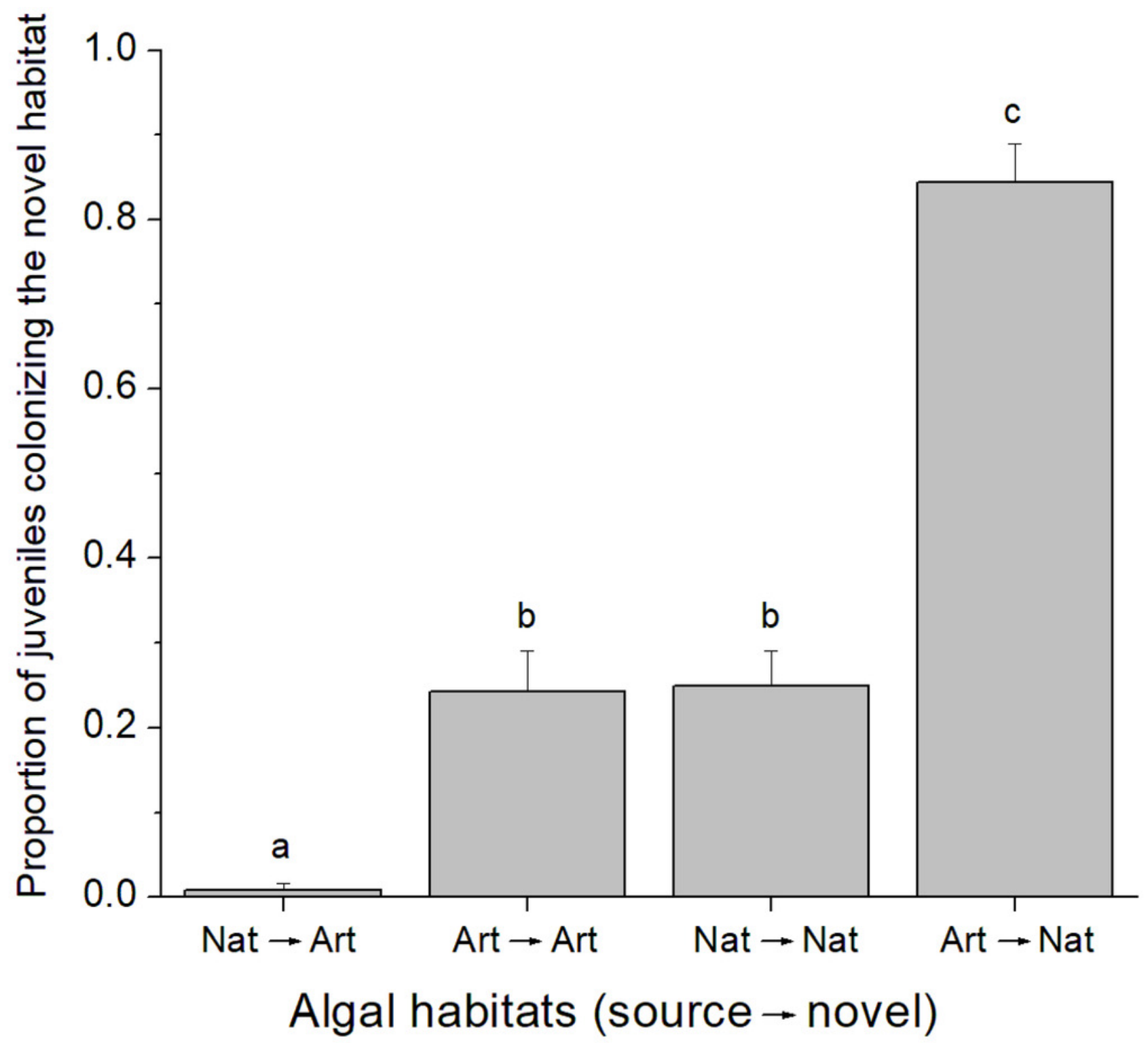


Figure 3

Abundance of juveniles of Cymadusa filosa that colonized algal experimental patches in the field. Different numbers of conspecific adult males $(0,4$ and 8$)$ were established in the algal patches when they were deployed in the field. Bars represent st 


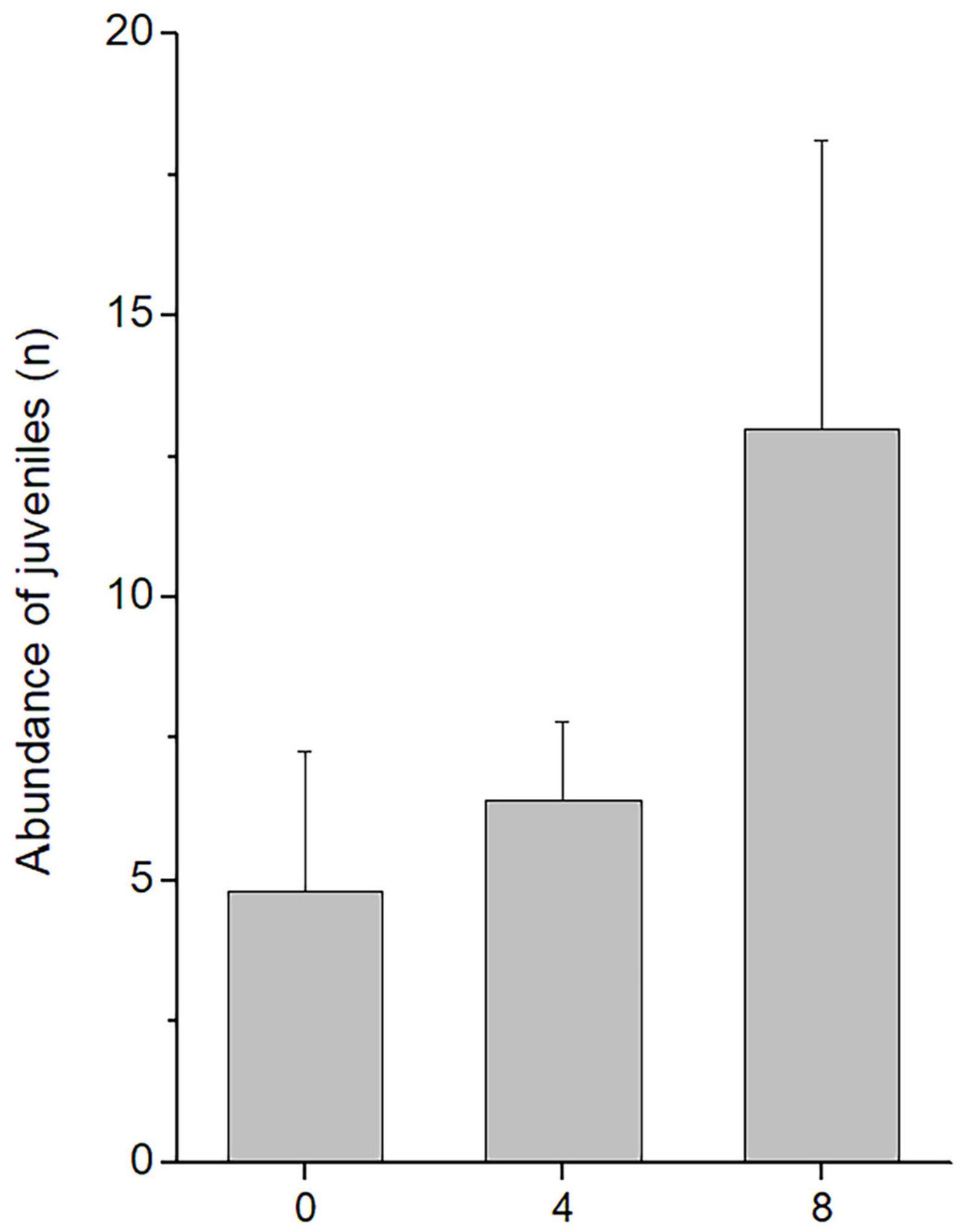

Number of adults in the algal patches 
Figure 4

Proportion of juveniles of Cymadusa filosa colonizing the novel habitat (natural alga with or without adults) when different source habitats (natural algal thallus, artificial algal and none) were provided to the juveniles in the laboratory. Bars re

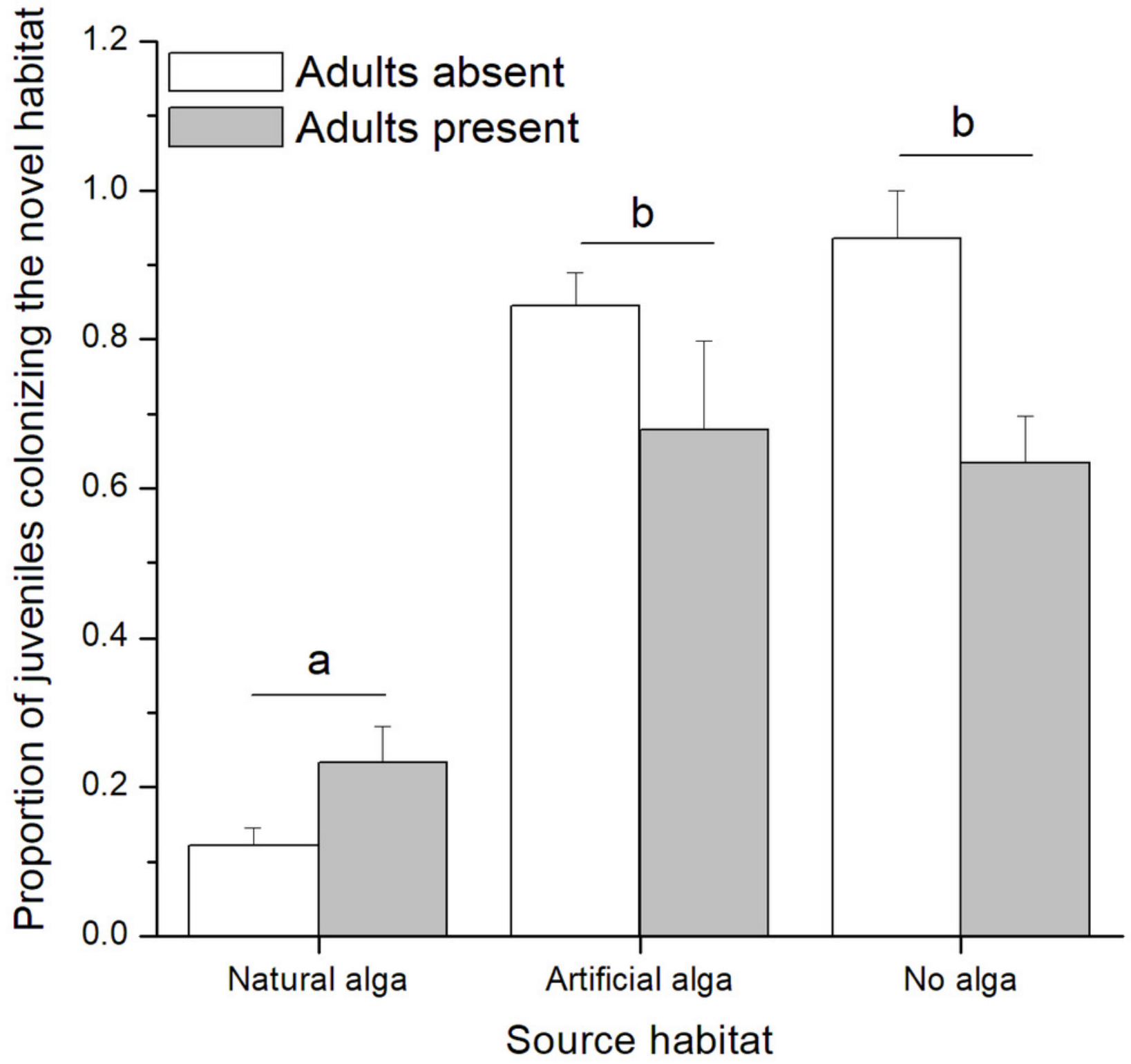




\section{Table 1 (on next page)}

Analysis of Deviance for GLM with Quasi-binomial distribution fitted to the proportion of juveniles from different source habitats colonizing natural algal thallus with or without adults at the laboratory experiment. 
1 Tables

2

3 Table 1. Analysis of Deviance for GLM with Quasi-binomial distribution fitted to the proportion

4 of juveniles from different source habitats colonizing natural algal thallus with or without adults

5 at the laboratory experiment.

\begin{tabular}{lcccccc}
\hline \multicolumn{1}{c}{ Source of variation } & $d f$ & Deviance & Residual $d f$ & Residual deviance & F & p \\
\hline NULL & --- & --- & 35 & 20.423 & --- & -- \\
Source habitat (SH) & 2 & 12.181 & 33 & 8.242 & 33.008 & $<0.001$ \\
Presence of adults & 1 & 0.779 & 32 & 7.462 & 4.223 & 0.049 \\
(PA) & 2 & 1.699 & 30 & 5.763 & 4.605 & 0.018 \\
SH X PA & & & & & & \\
\hline
\end{tabular}

